\title{
Factors leading to failure to diagnose pulmonary malignant tumors using endobronchial ultrasound with guide sheath within the target lesion
}

Yoichi Nishii ${ }^{1}$, Taro Yasuma ${ }^{2}$, Kentaro Ito ${ }^{1}$, Yuta Suzuki ${ }^{1}$, Fumiaki Watanabe ${ }^{1}$, Tetsu Kobayashi ${ }^{3}$, Kota Nishihama $^{2}$, Corina N. D'Alessandro-Gabazza², Hajime Fujimoto ${ }^{3}$, Esteban C. Gabazza ${ }^{2 *}$, Fumihiro Asano ${ }^{4}$,

Osamu Taguchi ${ }^{1}$ and Osamu Hataji ${ }^{1}$

\begin{abstract}
Background: The diagnostic yield of peripheral pulmonary lesions has significantly increased with the use of radial endobronchial ultrasound with guide sheath within the lesion. Here, we retrospectively evaluated factors leading to misdiagnosis of pulmonary malignant tumors using endobronchial ultrasound with the guide sheath within the lesion.

Methods: We assessed the final histopathological diagnosis of biopsy samples taken from 130 patients with lung malignant tumors that underwent endobronchial ultrasound with guide sheath within the lesion.

Results: Among 130 patients, 8 (6\%) showed no definite malignant findings in biopsy samples but the presence of malignant cells (primary lung cancer 7, diffuse large B cell lymphoma 1) was subsequently confirmed by histopathological study of specimens taken by computed tomography-guided needle biopsy or surgery. Of the eight cases with diagnostic failure, the size of the biopsy sample was insufficient in five due to technical difficulties during the diagnostic procedure, and the diagnosis of malignant tumor was difficult in five cases because of extensive scarring tissue or central necrosis.

Conclusions: The results of this study showed that technical difficulties and/or pathological heterogeneity of the tumor might lead to failure to diagnose lung malignant tumor in cases using endobronchial ultrasound with guide sheath within the lesion.
\end{abstract}

Keywords: Bronchoscopy, Diagnostic errors, Lung, Ultrasonography, Neoplasms

\section{Background}

The procedure of bronchoscopy for tissue sampling of lung peripheral masses has been traditionally carried out under fluoroscopic guidance, and the bronchial branch connected to the lesion has been classically estimated from the 2-dimensional lung computed tomography images taken prior to the bronchoscopic study [1]. However, the diagnostic yield of peripheral pulmonary lesions of less than $2 \mathrm{~cm}$ is very low (34\%) when this conventional bronchoscopic method is used [1-3]. Radial

\footnotetext{
* Correspondence: gabazza@doc.medic.mie-u.ac.jp

${ }^{2}$ Department of Immunology, Mie University Faculty and Graduate School of Medicine, Edobashi 2-174, Tsu-city, Mie 514-8507, Japan

Full list of author information is available at the end of the article
}

endobronchial ultrasound (EBUS) and virtual bronchoscopic navigation system have been recently developed to improve the diagnostic yield of bronchoscopic techniques [4]. Indeed, recent studies have shown that the combined use of both techniques have dramatically increased (> 80\%) the diagnostic yield of peripheral pulmonary lesions of less than $2 \mathrm{~cm}[2,3]$. Further, the diagnostic yield is even higher when the EBUS shows that the guide sheath is within the target lesion $[5,6]$. Nonetheless, about $10 \%$ of pulmonary malignant lesions are not diagnosed despite being the guide sheath within the lesion [4]. The cause of this diagnostic failure is unclear. The aim of the present study was to describe retrospectively the clinical and histopathological

(C) The Author(s). 2019 Open Access This article is distributed under the terms of the Creative Commons Attribution 4.0 International License (http://creativecommons.org/licenses/by/4.0/), which permits unrestricted use, distribution, and 
characteristics of cases with diagnostic failure after EBUS with the guide sheath within the lesion.

\section{Patients and methods}

We retrospectively evaluated 347 patients with lung mass that underwent EBUS with guide sheath (EBUSGS) at the Respiratory Center of Matsusaka Municipal Hospital between February 2015 and August 2016. Among 347 patients, 84 with benign lesion, 42 under follow-up, and 13 lost to follow-up were excluded from the study. Of the remaining 208 patients with lung mass, 26 with ground glass opacity and 13 with cavitation were excluded because it was difficult to confirm whether the guide sheath was within the lesion. During the EBUS-GS procedure performed in the remaining 169 patients, the guide sheath was within the target lesion in 132 cases, and among these, the histopathological study revealed malignant tumor in 122 cases and no malignant findings in 10 cases. Of these 10 cases, 2 were excluded because the final diagnosis of malignant tumor was possible only by clinical exclusion, and 8 underwent CT-guided needle biopsy or surgery for final diagnosis (Fig. 1). The histopathological diagnosis was malignant tumor in the 8 cases.

The bronchoscopic procedure was performed as previously described [2]. A flexible bronchoscope was inserted after spraying $2 \%$ lidocaine hydrochloride on the pharyngeal mucosa and intravenous administration of $2 \mathrm{mg}$ midazolam (SANDOZ Japan, Tokyo). Additional injection of midazolam was performed as required. The flexible bronchoscope used in the study was Olympus BF Type P260F (Olympus Medical Systems, Tokyo, Japan) with an external diameter of $4 \mathrm{~mm}$ and a channel diameter of $2 \mathrm{~mm}$ or Olympus BF Type P290 (Olympus Medical Systems, Tokyo, Japan) with an external diameter of $4.2 \mathrm{~mm}$ and a channel diameter of $2 \mathrm{~mm}$. Insertion of the bronchoscope was assisted using a

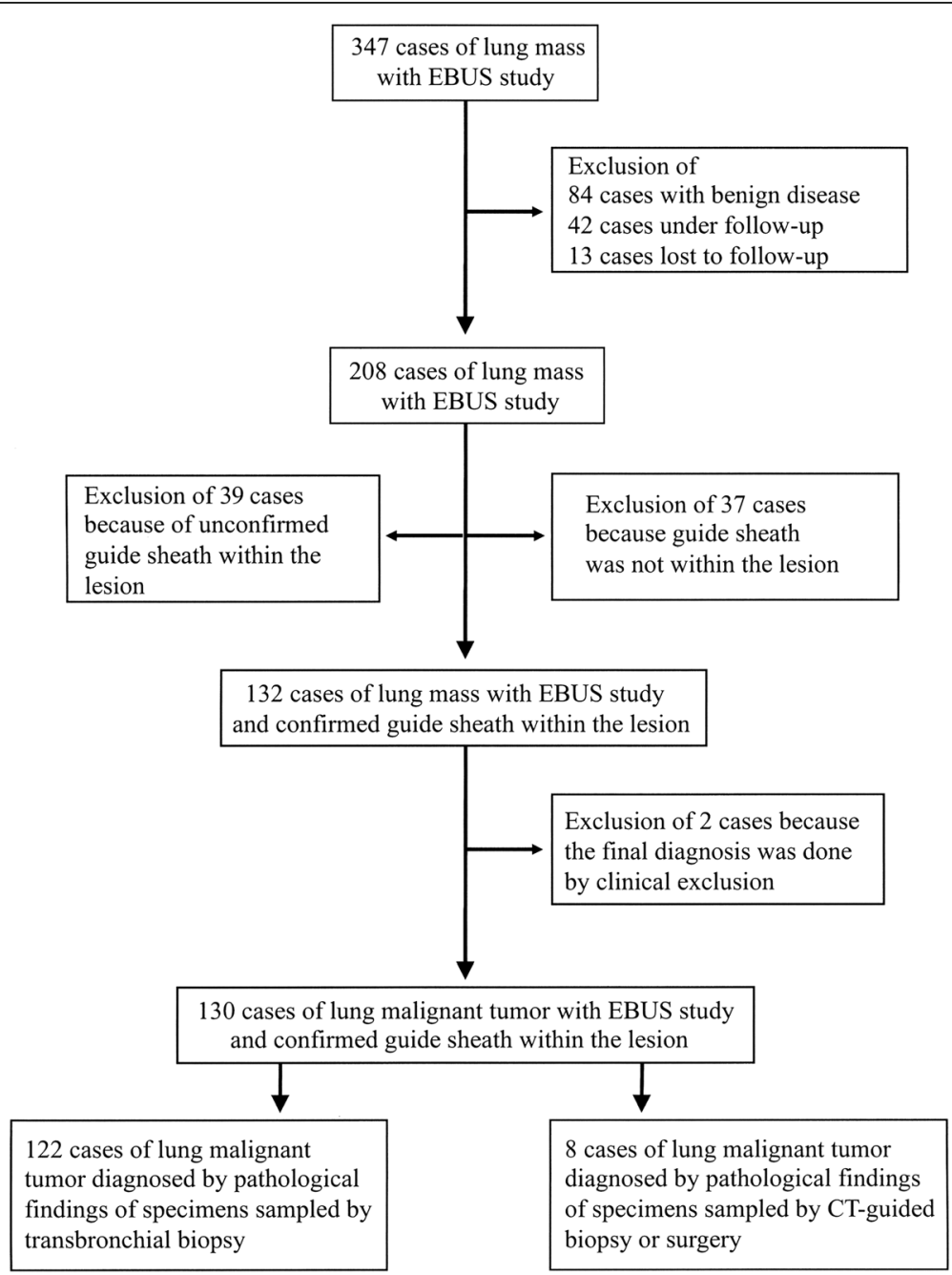

Fig. 1 Study selection procedure. The records of 347 patients with lung mass that underwent endobronchial ultrasound with guide sheath were evaluated and 130 cases with confirmed diagnosis and 8 cases with misdiagnosis were selected following the described criteria 
Table 1 Characteristics of the patients

\begin{tabular}{|c|c|c|c|}
\hline Variables & $\begin{array}{l}\text { Cases with } \\
\text { Misdiagnosis } \\
(n=8)\end{array}$ & $\begin{array}{l}\text { Cases with correct } \\
\text { diagnosis }(n=122)\end{array}$ & $\begin{array}{l}P \\
\text { values }\end{array}$ \\
\hline Median age (range) & $73(37-83)$ & $74(31-95)$ & 0.76 \\
\hline Sex & & & 0.27 \\
\hline Male & 4 & 84 & \\
\hline Female & 4 & 38 & \\
\hline $\begin{array}{l}\text { Lesion size (mm, } \\
\text { median range) }\end{array}$ & $27.8(15.0-48.0)$ & $32.9(5.5-81.0)$ & 0.30 \\
\hline Location & & & 0.058 \\
\hline Central & 0 & 11 & \\
\hline Intermediate & 0 & 41 & \\
\hline Peripheral & 8 & 70 & \\
\hline $\begin{array}{l}\text { Virtual bronchoscopic } \\
\text { navigation, } \mathrm{n}(\%)\end{array}$ & $8(100 \%)$ & $101(82.8 \%)$ & 0.35 \\
\hline $\begin{array}{l}\text { Rapid on site } \\
\text { cytology, n(\%) }\end{array}$ & $7(87.5 \%)$ & 89 (73.0\%) & 0.62 \\
\hline EBUS-image & & & 0.04 \\
\hline Type Ila & 1 & 0 & \\
\hline Type Ilb & 1 & 4 & \\
\hline Type IIla & 4 & 57 & \\
\hline Type IIIb & 2 & 57 & \\
\hline Unknown & 0 & 4 & \\
\hline Final diagnosis & & & 0.32 \\
\hline $\begin{array}{l}\text { Primary lung } \\
\text { cancer }\end{array}$ & 7 & 117 & \\
\hline $\begin{array}{l}\text { Malignant } \\
\text { lymphoma }\end{array}$ & 1 & 0 & \\
\hline $\begin{array}{l}\text { Metastatic lung } \\
\text { cancer }\end{array}$ & 0 & 5 & \\
\hline
\end{tabular}

virtual bronchoscopic navigation system (Bf-NAVI; Cybernet Systems, Tokyo) as described [7] . The virtual bronchoscopic images were prepared using the computed tomography scan (TSX-101A/QA, Canon Medical Corporation, Tochigi, Otawara, Japan) data of the lungs as previously described [2]. A radial type EBUS probe of $1.4 \mathrm{~mm}$ (UM-S20-17S; Olympus Medical Systems, Tokyo) was introduced with a guide sheath (SG200C; Olympus Medical Systems, Tokyo, Japan) through an endoscopic channel to visualize the lung lesions. Lung tissue samples were collected using forceps of $1.5 \mathrm{~mm}$ (FB-233D;Olympus Medical Systems, Tokyo, Japan) inserted into the guide sheath. After confirming visualization of the lesion, the EBUS probe was withdrawn. Brushing and washing were performed after completing the transbronchial biopsy.

\section{Statistical analysis}

Data are expressed as the median and range. The different between two groups with continuous variable was evaluated

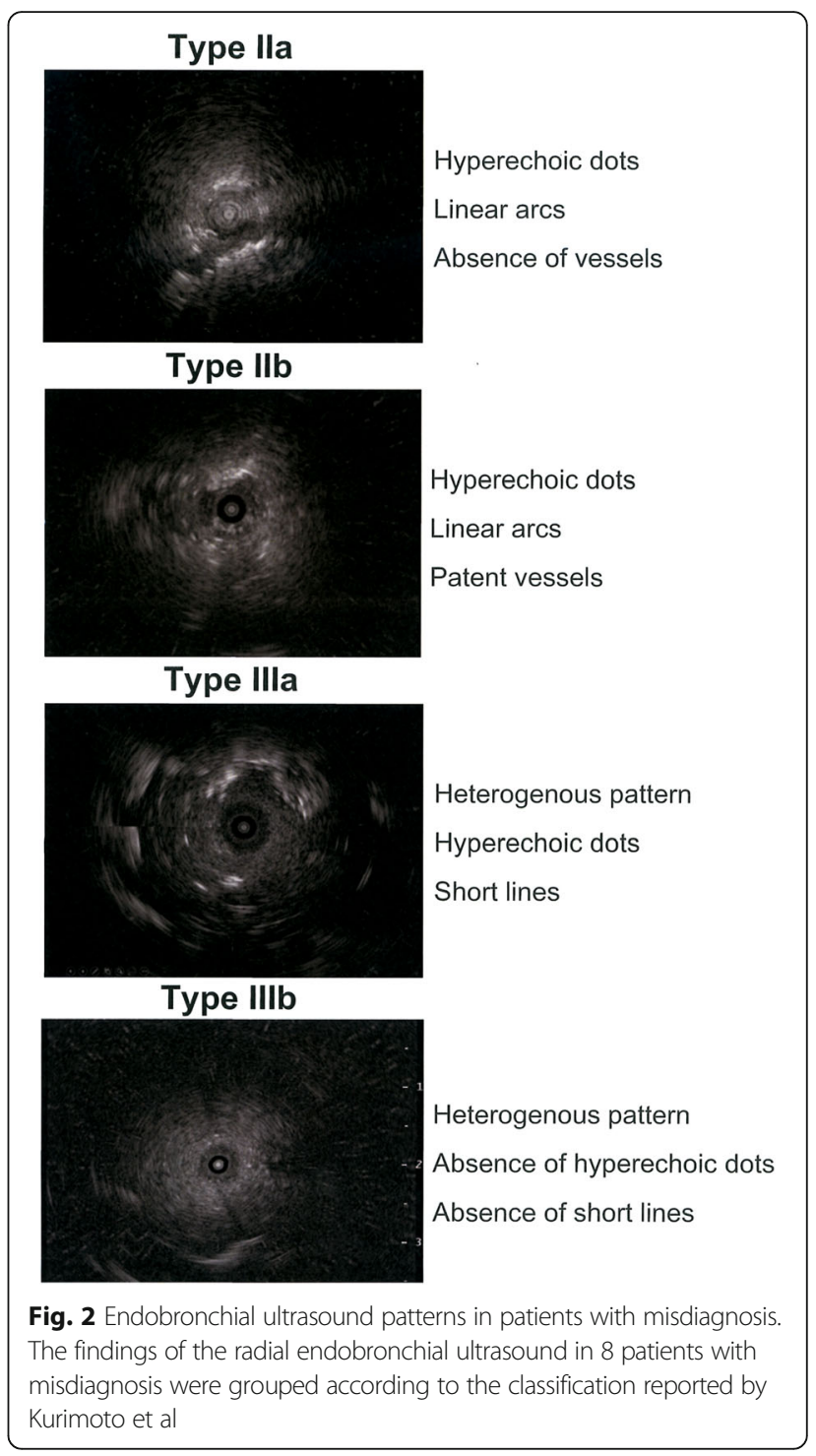

by student test and the difference in distribution by Fisher's exact test. Statistical analyses were done using the Graph Prism version 8.0.1 (Graphpad Software, San Diego, CA). A $p<0.05$ was considered as statistical significance.

\section{Results}

The backgrounds and characteristics of the patients are described in Table 1. There was no significant different in the age, sex distribution, tumor size, tumor location or in the number of times the virtual bronchoscopic navigation and rapid on site cytology was performed between misdiagnosis and correct diagnosis groups (Table 1). The lesions were grouped according to EBUS findings based on the classification proposed by Kurimoto et al. (Fig. 2) as follows: type IIa (hyperechoic dots and linear arcs without vessels; $n=1$ ), type IIb (hyperechoic dots and linear arcs with patent 
a

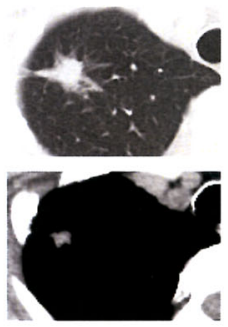

d

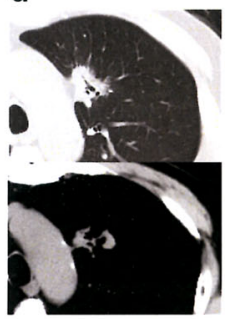

g

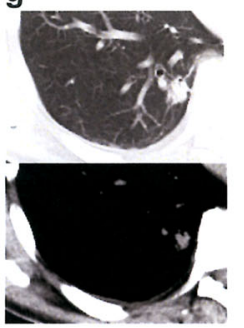

j

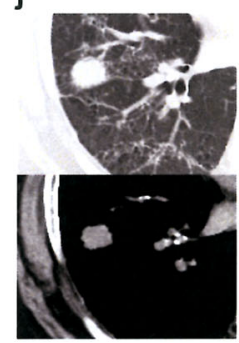

b. EBUS image type IIla

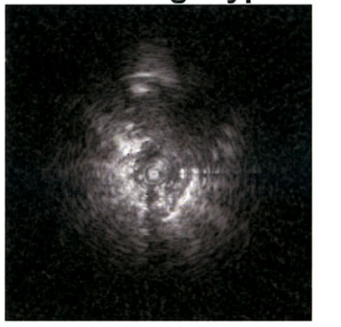

e. EBUS image type IIla

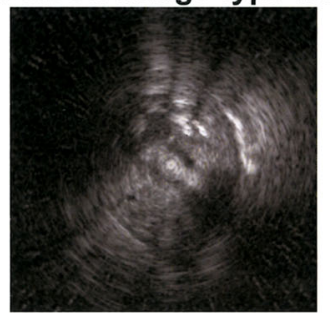

h. EBUS image type IIla



k. EBUS image type IIIb

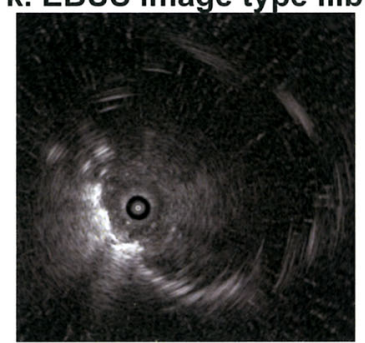

c. Sampling by surgical procedure

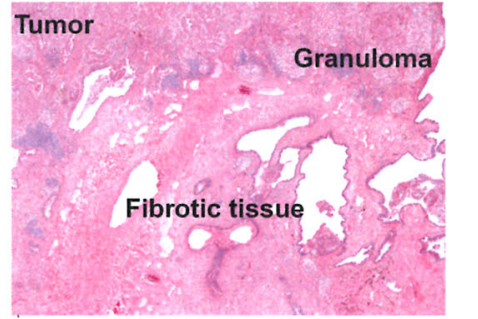

f. Sampling by surgical procedure

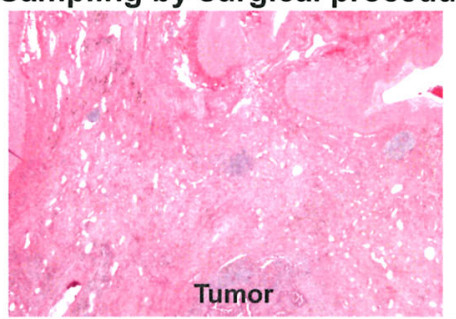

i. Sampling by TBB

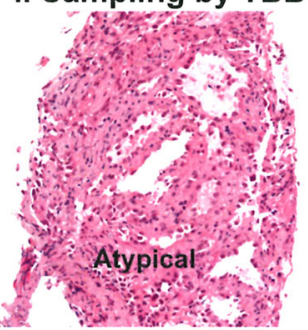

I. Sampling by CTNB

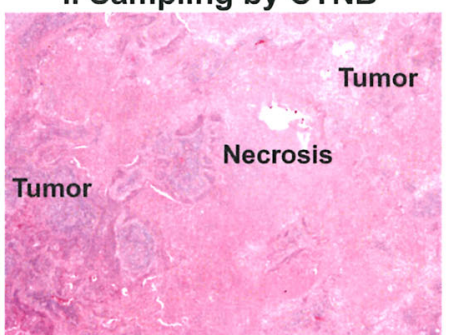

Fig. 3 Computed tomography, endobronchial ultrasound and histopathological findings. Case 3 (a, b, c): tumor with fibrotic and granulomatous tissue. Case $4(\mathbf{d}, \mathbf{e}, \mathbf{f})$ : tumor with areas of fibrosis and necrosis. Case $5(\mathbf{g}, \mathbf{h}, \mathbf{i})$ : tissue sampling by transbronchial biopsy with tissue showing atypical cells. Case $6(\mathbf{j}, \mathbf{k}, \mathbf{l})$ : tumor with central necrosis. EBUS, endobronchial ultrasound; CTNB, CT-guided needle biopsy

vessels; $n=1$ ), type IIIa (heterogeneous pattern with hyperechoic dots and short lines; $n=4$ ) and IIIb (heterogeneous pattern without hyperechoic dots or short lines; $n=2$ ) (Fig. 3) [8]. EBUS images showed heterogeneous patterns in cases 3 to 8 , and there was significant difference in the EBUS pattern between both misdiagnosis and correct diagnosis groups (Table 1). There were 7 cases of primary lung cancer and 1 case of diffuse large B cell lymphoma but there was no significant difference in the final diagnosis between both misdiagnosis and correct diagnosis groups (Table 1).

Transbronchial biopsy was conducted three times in one case and over five times in the other cases. The diagnostic report of cytological smear disclosed negative findings in cases 1, 2, 3 and 6, presence of atypical cells in cases 5 and 7, and suspicious findings of cancer in cases 4 and 8 . The report of histopathological examination of biopsy samples collected during bronchoscopy and EBUS-GS showed negative findings in cases 2 and 3, atypical cells in cases $1,3,5$ and 7 , and insufficient amount of tissue in cases 2 and 8. During the bronchoscopic procedure, case 1 had persistent cough, cases 2 and 8 showed irregular respiratory rhythms and cases 1 , 2, 4 and 5 presented bronchial bifurcations with steep angles. Tissue sampling was not technically difficult in cases 3, 6 and 7 (Table 2).

Histopathological examination of lung tissue specimens obtained by CT-guided needle biopsy or during 
Table 2 Factors associated with diagnostic failure

\begin{tabular}{|c|c|c|c|c|c|}
\hline Cases & Bronchi & EBUS-i & Diagnosis & Technical factors & Pathological factors \\
\hline 1 & $L t B 1+2 a$ & $\| \mathrm{ll}$ & WDadeno & $\begin{array}{l}\text { Bending and difficult } \\
\text { stabilization of guide sheath }\end{array}$ & Tumor with central necrosis \\
\hline 2 & RtB6C & $11 \mathrm{~b}$ & MD adeno & $\begin{array}{l}\text { Bending and difficult stabilization } \\
\text { of guide sheath }\end{array}$ & $\begin{array}{l}\text { Homogeneous distribution of } \\
\text { tumor cells }\end{array}$ \\
\hline 3 & RtB1bii & Illa & MD adeno & No difficulty & $\begin{array}{l}\text { Heterogeneous tissue. Tumor } \\
\text { cells in granulomatous and } \\
\text { fibrotic tissue }\end{array}$ \\
\hline 4 & LtB3ci & Illa & MD adeno & Bending of guide sheath & Tumor central necrosis \\
\hline 5 & RtB10bii & IIla & WD adeno & $\begin{array}{l}\text { Bending and difficult stabilization } \\
\text { of guide sheath }\end{array}$ & $\begin{array}{l}\text { Tumor cells with predominant } \\
\text { distribution in central areas }\end{array}$ \\
\hline 6 & RtB4aiß & $\| l l b$ & PD SCC & No difficulty & Tumor with central necrosis \\
\hline 7 & RtB2bii & Illa & WDadeno & No difficulty & Tumor with central necrosis \\
\hline 8 & LtB8biia & $\| l l b$ & DLBCL & Difficult stabilization of guide sheath & $\begin{array}{l}\text { Homogeneous distribution of } \\
\text { tumor cells }\end{array}$ \\
\hline
\end{tabular}

EBUS-1 endobronchial ultrasound image, LtB left bronchus, RtB right bronchus, adeno adenocarcinoma, SCC squamous cell carcinoma, WD well-differentiated, MD moderately differentiated, $P D$ poorly differentiated, $D L B C L$ diffuse large B cell lymphoma

surgery disclosed tumor central necrosis in cases $1,4,6$ and 7 , extensive areas of granulomatous and fibrotic tissue in case 3 , lack of cancer cells in peripheral areas in case 5, and homogeneous distribution of cancer cells in cases 2 and 8 (Table 2; Fig. 3).

\section{Discussion}

The diagnostic yield of peripheral pulmonary lesions of less than $3 \mathrm{~cm}$ by bronchoscopy has substantially improved with the use of R-EBUS or virtual bronchoscopic navigation reaching 60 to $80 \%$ when both virtual bronchoscopic navigation and EBUS-GS are used in combination $[4,9]$. The diagnostic yield is particularly high when the EBUS guide sheath is placed within the target lesion [4]. However, misdiagnosis has been reported even in cases with the guide sheath within the lesion but the cause remains unclear. Here, we reported 8 cases of diagnostic failure despite being the guide sheath within the tumor site. Six patients (cases 3, 4, 5, 6, 7, 8) from the misdiagnosis group showed heterogeneous EBUS images and the EBUS pattern was significantly different between both misdiagnosis and correct diagnosis groups. Further, six patients (cases 1, 3, 4, 5, 6,7) of the misdiagnosis group also showed inhomogeneous distribution of malignant cells within the tumor. Therefore, heterogeneity in the EBUS findings and in the intra-tumoral distribution of malignant cells appears to be important factors leading to failure of diagnosis. Sampling of large-sized or multiple specimens may improve the diagnostic yield. Yamada et al reported diagnostic yield of $96.5 \%$ in cases with 5 biopsied specimens and $100 \%$ in cases with 10 specimens [6]. The use of large forceps or cryobiopsy may also be an alternative approach to collect large-sized specimens [10,11].

We found here that technical difficulty is another important cause of misdiagnosis. Sample collection was difficult in 5 patients (cases 1, 2, 4, 5) because steep angle of the bronchial branch restrained complete bending of the bronchoscope tip. In these cases, the use of ultra-thin bronchoscope in combination with R-BUS may help to overcome technical difficulties and to improve diagnostic yield as reported by Oki et al [12]. We also experienced technical difficulty in one patient with persistent cough (case 1) and in 2 patients with irregular respiratory rhythm (cases 2,8 ). We believe that insufficient sedation during the bronchoscopic procedure could have been the cause. In this regards, the guidelines of the British Thoracic Society recommends sedation with benzodiazepines or/and opioids to improve tolerance and facilitate diagnostic procedures during bronchoscopy [13]. Adequate sedation can prevent throat reflex and coughing and facilitate specimen sampling [13].

\section{Conclusion}

In brief, the results of this study showed that technical difficulties and/or heterogeneity of EBUS and histopathological findings of the tumor might lead to failure to diagnose lung malignant tumor even in cases using EBUS with the guide sheath within the tumor. The cause of diagnosis failure reported in this study may serve as important hints for developing countermeasures to improve the diagnostic yield in patients with lung peripheral malignant tumors.

\section{Abbreviations}

adeno: Adenocarcinoma; CT: Computed tomography; DLBCL: Diffuse large B cell lymphoma; EBUS-i: Endobronchial ultrasound image; GS: Guide sheath; LtB: Left bronchus; MD: Moderately differentiated; PD: Poorly differentiated; R-EBUS: Radial endobronchial ultrasound; RtB: Right bronchus;

SCC: Squamous cell carcinoma; WD: Well-differentiated

Acknowledgements

Not applicable. 


\section{Authors' contributions}

$\mathrm{YN}, \mathrm{TK}, \mathrm{OH}$, and ECG contributed in conceptualization and idea of the study. $\mathrm{KI}, \mathrm{YS}, \mathrm{FW}, \mathrm{TY}, \mathrm{KN}, \mathrm{CND}-\mathrm{G}$ and HF made contributions in the supervision and data analysis. TY, ECG, FA and CND-G edited the manuscript. OT and OH contributed in resources and in the interpretation of the data. All authors read and approved the final manuscript.

\section{Funding}

No grant was received for conducting this study.

\section{Availability of data and materials}

The data used and/or analyzed during the current study are available from the corresponding author on reasonable request.

\section{Ethics approval and consent to participate}

Informed consent was obtained from all patients before the diagnostic procedures. The Institutional Review Board of Matsusaka Municipal Hospital approved the study protocol (Approval No.180601-6-5; Date: 2018/6/14), and the study was performed following the Principles of Helsinki Declaration.

\section{Consent for publication}

Consent has been obtained for publication of images.

\section{Competing interests}

The authors declare that they have no competing interests.

\section{Author details}

'Respiratory Center, Matsusaka Municipal Hospital, Tonomachi 1550, Matsusaka, Mie 515-8544, Japan. ${ }^{2}$ Department of Immunology, Mie University Faculty and Graduate School of Medicine, Edobashi 2-174, Tsu-city, Mie 514-8507, Japan. ${ }^{3}$ Department of Pulmonary and Critical Care Medicine, Mie University Faculty and Graduate School of Medicine, Edobashi 2-174, Tsu, Mie 514-8507, Japan. ${ }^{4}$ Gifu Prefectural General Medical Center, Noisshiki 4-6-1, Gifu, Gifu 500-8717, Japan.

Received: 5 March 2019 Accepted: 3 September 2019

Published online: 12 September 2019

\section{References}

1. Dhillon SS, Harris K. Bronchoscopy for the diagnosis of peripheral lung lesions. J Thorac Dis. 2017;9(Suppl 10):S1047-58.

2. Ishida T, Asano F, Yamazaki K, Shinagawa N, Oizumi S, Moriya H, Munakata M, Nishimura M, Virtual Navigation in Japan Trial, G. Virtual bronchoscopic navigation combined with endobronchial ultrasound to diagnose small peripheral pulmonary lesions: a randomised trial. Thorax. 2011;66(12):1072-7.

3. Rivera MP, Mehta AC, Wahidi MM. Establishing the diagnosis of lung cancer: diagnosis and management of lung cancer, 3rd ed: American College of Chest Physicians evidence-based clinical practice guidelines. Chest. 2013; 143(5 Suppl):e142S-65S.

4. Asano F, Eberhardt R, Herth FJ. Virtual bronchoscopic navigation for peripheral pulmonary lesions. Respiration. 2014;88(5):430-40.

5. Kurimoto N, Miyazawa T, Okimasa S, Maeda A, Oiwa H, Miyazu Y, Murayama M. Endobronchial ultrasonography using a guide sheath increases the ability to diagnose peripheral pulmonary lesions endoscopically. Chest. 2004;126(3):959-65.

6. Yamada N, Yamazaki K, Kurimoto N, Asahina H, Kikuchi E, Shinagawa N, Oizumi S, Nishimura M. Factors related to diagnostic yield of transbronchial biopsy using endobronchial ultrasonography with a guide sheath in small peripheral pulmonary lesions. Chest. 2007:132(2):603-8.

7. Tachihara M, Ishida T, Kanazawa K, Sugawara A, Watanabe K, Uekita K, Moriya H, Yamazaki K, Asano F, Munakata M. A virtual bronchoscopic navigation system under $X$-ray fluoroscopy for transbronchial diagnosis of small peripheral pulmonary lesions. Lung Cancer. 2007;57(3):322-7.

8. Kurimoto N, Murayama M, Yoshioka S, Nishisaka T. Analysis of the internal structure of peripheral pulmonary lesions using endobronchial ultrasonography. Chest. 2002;122(6):1887-94.

9. Ali MS, Trick W, Mba Bl, Mohananey D, Sethi J, Musani Al. Radial endobronchial ultrasound for the diagnosis of peripheral pulmonary lesions: a systematic review and meta-analysis. Respirology. 2017;22(3):443-53.
10. Schuhmann M, Bostanci K, Bugalho A, Warth A, Schnabel PA, Herth FJ, Eberhardt R. Endobronchial ultrasound-guided cryobiopsies in peripheral pulmonary lesions: a feasibility study. Eur Respir J. 2014;43(1):233-9.

11. Tomassetti S, Wells AU, Costabel U, Cavazza A, Colby TV, Rossi G, Sverzellati N, Carloni A, Carretta E, Buccioli M, Tantalocco P, Ravaglia C, Gurioli C, Dubini A, Piciucchi S, Ryu JH, Poletti V. Bronchoscopic lung Cryobiopsy increases diagnostic confidence in the multidisciplinary diagnosis of idiopathic pulmonary fibrosis. Am J Respir Crit Care Med. 2016;193(7):745-52.

12. Oki M, Saka H, Ando M, Asano F, Kurimoto N, Morita K, Kitagawa C, Kogure Y, Miyazawa T. Ultrathin bronchoscopy with multimodal devices for peripheral pulmonary lesions. A randomized trial. Am J Respir Crit Care Med. 2015;192(4):468-76.

13. Du Rand IA, Barber PV, Goldring J, Lewis RA, Mandal S, Munavvar M, Rintoul RC, Shah PL, Singh S, Slade MG, Woolley A, British Thoracic Society Interventional Bronchoscopy Guideline, G. British Thoracic Society guideline for advanced diagnostic and therapeutic flexible bronchoscopy in adults. Thorax. 2011;66(Suppl 3):iii1-21.

\section{Publisher's Note}

Springer Nature remains neutral with regard to jurisdictional claims in published maps and institutional affiliations.

\section{Ready to submit your research? Choose BMC and benefit from:}

- fast, convenient online submission

- thorough peer review by experienced researchers in your field

- rapid publication on acceptance

- support for research data, including large and complex data types

- gold Open Access which fosters wider collaboration and increased citations

- maximum visibility for your research: over $100 \mathrm{M}$ website views per year

At $\mathrm{BMC}$, research is always in progress.

Learn more biomedcentral.com/submissions 